\title{
Predictive value of random blood glucose versus fasting blood glucose on in-hospital adverse events in patients with ST-segment elevation acute myocardial infarction
}

\author{
Yuhan Qin ${ }^{1}$, Gaoliang Yan², Yong Qiao ${ }^{2}$, Dong Wang ${ }^{2}$, Erfei Luo', Jiantong Hou ${ }^{1}$ and Chengchun Tang ${ }^{2 *}$ (D)
}

\begin{abstract}
Background: We aim to find out the relationship between random blood glucose (RBG), fasting blood glucose (FBG) and in-hospital adverse events in ST-segment elevation acute myocardial infarction (STEMI) patients. We evaluate and compare the predictive value of RBG and FBG on in-hospital adverse events, and give an appropriate cut-off value of RBG and FBG.

Method: A retrospective study enrolled 958 consecutive AMI patients undergoing emergency coronary angiography at Zhongda Hospital were enrolled from January 1, 2016, to December 31, 2018 was performed. RBG and FBG, baseline data and adverse events were recorded. Major adverse cardiovascular and cerebrovascular events (MACCE) were defined as death, nonfatal recurrent myocardial infarction and stroke. Other adverse events included malignant arrhythmia, cardiac shock and hemorrhage. Patients with RBG $>11.1 \mathrm{mmol} / \mathrm{L}$ were divided into elevated RBG group. Patients with FBG $>6.1 \mathrm{mmol} / \mathrm{L}$ were divided into elevated FBG group. The incidence of in-hospital adverse events were compared in elevated RBG/FBG group and the control group. ROC curve was used to evaluate the predictive value of RBG and FBG on in-hospital adverse events.

Result: The incidence of death, hemorrhage, cardiac shock and malignant arrhythmia significantly increases in elevated RBG and FBG group. Binary logistic regression showed that age, hypertension, diabetes, FBG and RBG were independent risk factors for in-hospital adverse events in STEMI patients. The AUC and 95\% Cl of RBG and FBG in predicting death of AMI patients were $0.789,0.759 \sim 0.816 ; 0.810,0.783 \sim 0.835$, respectively. The cut-off values were 13.82 and $7.35 \mathrm{mmol} / \mathrm{L}$. RBG and FBG also had fine predictive value on cardiac shock and malignant arrhythmia, no statistical difference was found in the predictive value on in-hospital adverse events ( $P=0.462, P=0.570, P=0.694$ ).

Conclusion: Incidence of in-hospital adverse events significantly increases in AMl patients combined with elevated RBG or FBG. Both RBG and FBG were independent risk factors for in-hospital adverse events, they had good value on predicting in-hospital adverse events and there was no statistical difference in their predictive value.
\end{abstract}

Keywords: RBG, FBG, STEMI, Adverse events, Prognosis

\footnotetext{
* Correspondence: tangchengchun@hotmail.com

${ }^{2}$ Department of Cardiology, Zhongda Hospital affiliated to Southeast

University, Nanjing 210009, People's Republic of China

Full list of author information is available at the end of the article
}

(c) The Author(s). 2020 Open Access This article is distributed under the terms of the Creative Commons Attribution 4.0 International License (http://creativecommons.org/licenses/by/4.0/), which permits unrestricted use, distribution, and reproduction in any medium, provided you give appropriate credit to the original author(s) and the source, provide a link to the Creative Commons license, and indicate if changes were made. The Creative Commons Public Domain Dedication waiver (http://creativecommons.org/publicdomain/zero/1.0/) applies to the data made available in this article, unless otherwise stated. 


\section{Background}

In modern countries, mortality after AMI has been significantly decreased with coronary revascularization developments [1], nevertheless, AMI still plays an important role in cardiovascular disease, and account for a large proportion in the causes of human death. Diabetes mellitus is becoming a burden on society because of its endemic increase and high cardiovascular morbidity and mortality [2]. The morbidity and mortality of cardiovascular disease in diabetic patients is $2-3$ times higher than that in normal glucose population [3]. Macrovascular complications such as myocardial infarction and stroke account for $80 \%$ of all deaths in patients with T2DM [4]. Moreover, elevated blood glucose is common in patients with AMI.

Epidemiological studies have demonstrated that hyperglycemia is an independent risk factor for poor prognosis in AMI patients, whether or not having diabetes history [5]. The prognostic value of the blood glucose in AMI patients was first suggested in 1975 [6], numerous studies have researched the correlation between hyperglycemia and adverse outcome in AMI patients since then. Hyperglycemia on admission is associated with higher mortality incidence, larger infarct size, impaired left ventricular function and poor clinical prognosis after AMI [5], Researches demonstrated a linear correlation between blood glucose on admission and AMI mortality. Mikhail Kosiborod and his colleagues demonstrated that persistent hyperglycemia during AMI is more predictive of mortality than admission blood glucose [7]. Among non-diabetic patients with AMI, elevated admission blood glucose is also proved to be associated to more severe multivessel coronary disease and deteriorates the short-term prognosis [8]. Furthermore, prediction models for long-term mortality in AMI patients were developed for risk stratification, closer follow-up and secondary prevention are necessary in high-risk patients [9].

Elevated fasting glucose is common in patients with acute myocardial infarction (AMI) and is associated with an increased short-term mortality [10]. It is reported IFG as well as IGT is an independent predictor of allcause mortality in AMI patients [11]. A Korean prospective study including more than 1 million participants revealed that fasting glucose between $6.1-6.9 \mathrm{mmol} / \mathrm{L}$ was significantly related to increased risk of AMI [12], in the 4 year-follow-up Framingham Heart Study enrolled 4138 participants, IFG was associated with a higher cardiovascular disease risk in women but not in men [13]. There is no clear cut-off value of blood glucose to predict in-hospital poor prognosis. In this research, we aim to evaluate and compare the predictive value of RBG and FBG on in-hospital adverse events and provide an appropriate cut-off value for RBG and FBG to predict in-hospital adverse events.

\section{Methods}

\section{Study population}

A total of 958 consecutive patients with AMI underwent emergency coronary angiography in the Department of Cardiology, Zhongda Hospital affiliated to Southeast University, were enrolled from January 1, 2016 to December 31, 2018. The enrollment criteria were: 1 . Patients with AMI underwent emergency coronary angiography; 2. Aged 18-80; exclusion criteria were as followed: 1. People who were allergic to iodine or iodine contrast agents; 2 . Patients with intensive hemodynamic instability, severe liver or kidney dysfunction, severe infectious diseases, advanced malignant tumors, severe hematological diseases, or incomplete clinical data; all patients signed informed consent before enrollment.

\section{Study methods}

Baseline data including demographic data, blood pressure, Killip grade, anamnesis and personal history were all recorded. Standard methods were used to measure the resting systolic blood pressure, diastolic blood pressure and BMI [14]. The Hematological examination indicators including plasma blood glucose were measured in the laboratory of our hospital. Echocardiography parameters, medications and coronary angiography data were also recorded. Further information can be found in previous publication [15].

In-hospital adverse events were defined as: major adverse cardiovascular and cerebrovascular events (MACCE) including death, recurrent nonfatal myocardial infarction, and other in-hospital adverse events including hemorrhage, cardiogenic shock and malignant arrhythmia. After effective coronary intervention therapy, chest pain and TNI significantly improved. Recurrent nonfatal myocardial infarction is defined as chest pain appeared again, TNI increased again during hospitalization, and coronary angiography confirmed the recurrence of AMI. Hemorrhage referred to lifethreatening hemorrhage associated with the use of antiplatelet and anticoagulant drugs such as massive gastrointestinal hemorrhage and intracranial hemorrhage.

Hyperglycemia: The American Diabetes Association defines hospital related hyperglycemia as FBG >6.9 $\mathrm{mmol} / \mathrm{L}$ or RBG > $11.1 \mathrm{mmol} / \mathrm{L}$ without diabetes history, diabetic patients who are always above the normal blood glucose upper limit could also be classified into hyperglycemia group (14). In the research, RBG > $11.1 \mathrm{mmol} / \mathrm{L}$ was defined as elevated RBG regardless of a history of diabetes. In addition, FBG $>6.1 \mathrm{mmol} / \mathrm{L}$ was defined as elevated FBG. Patients admitted with RBG $<11.1 \mathrm{mmol} /$ $\mathrm{L}$ were included in the control RBG group and patients with $\mathrm{FBG}<6.1 \mathrm{mmol} / \mathrm{L}$ were included in the control FBG group. Venous blood was collected and RBG was tested as soon as the patients were admitted to the 
hospital before starting treatments such as revascularization, FBG was detected by collecting venous blood on the next morning after admission to the hospital. RBG and FBG were all measured in all patients.

Malignant arrythmia: Ventricular fibrillation, ventricular tachycardia, polymorphic Ventricular precontraction, paroxysmal supraventricular tachycardia.

Smoking: continuous or cumulative smoking for at least 6 months in a lifetime.

ST-segment elevation myocardial infarction referred to the STEMI criteria according to the fourth universal definition of myocardial infarction [16].

\section{Statistical analysis}

SPSS 19.0 and MedCalc v18.11.3 software were used for statistical analyses. Categorial data was expressed as cases and percentages, and the $\chi^{2}$ test was used for analysis. Continuous data was expressed as mean \pm Standard deviation, and compared using the independent samples t-test. Non-normally distributed numerical data were expressed as median and 25th-75th interquartile range, and compared using a rank-sum test. Univariate and binary logistic regression analysis were used to determine whether FBG and RBG were independent risk factors for in-hospital adverse events. MedCalc software was used to assess the predictive value of RBG and FBG in in-hospital adverse events and to assess predictive value difference between RBG and FBG. In all analyses, $P<0.05$ was taken to indicate statistical significance.

\section{Results}

Comparison of baseline data, hematological parameters and coronary angiography data between elevated RBG group and control group

Our research found that of 958 patients with AMI who underwent emergency coronary angiography, more than one quarter of patients (265) had elevated RBG, 98 (36.98\%) in them denied a history of diabetes.

There were significant differences in sex, age, hypertension, diabetes, previous MI, cerebral infarction, CKD, smoking, Killip class I, Killip class IV, BNP, WBC count, ALT, RBG, eGFR, FBG, TG, TC, HDL-C, LDL-C, LVEF, clopidogrel, ticagrelor, ACEI/ARBs, IABP, single-vessel lesion, double-vessel lesions and left main lesion between elevated RBG group and control group $(P<0.05)$. No significant statistical differences in the remaining indexes (Table 1).

Comparison of baseline data, hematological parameters and coronary angiography data in elevated FBG group and normal FBG group

Over three-fifths of patients had elevated fasting blood glucose, and up to 347 (59.22\%) were non-diabetic. There were significant differences in sex, BMI, diabetes, cerebral infarction, smoking, Killip class I, Killip class IV, TNI, Myo, BNP, WBC, RBG, ALT, AST, FBG, HDLC, LVEF, clopidogrel, ticagrelor, ACEI/ARB, furosemide, antisterone, IABP, single-vessel disease, triple-vessel disease, number of stents and left main lesion between the elevated FBG group and the normal FBG group $(P<$ 0.05) (Table 2).

\section{The incidence of in-hospital adverse events in elevated} RBG patients, elevated FBG patients and control group In the elevated RBG group, 56 patients died, 6 patients had nonfatal recurrent MI, 6 patients underwent target vessel revascularization, 1 patient had a stroke, 9 patients had hemorrhage, 57 patients suffered cardiogenic shock, and 25 patients had Malignant arrhythmia. Chi-square analysis showed that the incidence of death, cardiogenic shock, malignant arrhythmia and hemorrhage in elevated RBG group were all significantly higher than that in control group $(P<0.001, P=0.014, \mathrm{P}<0.001, \mathrm{P}<0.001)$. In the FBG-elevated group, 72 patients died, 7 patients had non-fatal recurrent MI, 7 patients had target vessel revascularization, 1 patient had a stroke, 20 had hemorrhage, and 89 patients suffered cardiogenic shock, 32 patients developed malignant arrhythmia. Chi-square analysis showed that the incidence of death, cardiogenic shock, malignant arrhythmia and hemorrhage significantly increased in FBG elevated group than in normal FBG group $(P<0.001, P=0.013, P<0.001, P=0.003)$. The incidence of non-fatal recurrent myocardial infarction, target vessel revascularization and stroke were relatively low in both elevated RBG and elevated FBG group, no statistical difference were found between elevated RBG, elevated FBG group and control group (Table 3).

\section{Binary logistic regression analysis for in-hospital adverse events}

Binary logistic regression showed that age, hypertension, diabetes, FBG and RBG were all independent risk factors for in-hospital adverse events in ST-segment elevation myocardial infarction patients $(P=0.037, P=0.039, P=$ $0.043, \mathrm{P}=0.043, P=0.048$, respectively; the corresponding $95 \% \mathrm{CI}=1.39-2.07,1.15-1.67,1.79-3.85,1.12-1.98$, 1.04-1.63, respectively) (Table 4).

\section{ROC curve}

The AUC and 95\% CI of RBG and FBG for predicting in-hospital death in AMI patients were 0.789, 0.759 0.816, $\quad(P<0.0001) ; \quad 0.810, \quad 0.783 \sim 0.835 \quad(\mathrm{P}<$ $0.0001)$ respectively. The cut-off values of RBG and FBG were 13.82 and $7.35 \mathrm{mmol} / \mathrm{L}$, respectively, the corresponding sensitivity and specificity were $61.11,86.44 \%$; 90.62, 68.05\%, respectively. There was no significant difference in predicting in-hospital death between them $(P=0.462)$ (Fig. 1). 
Table 1 Comparison of baseline data, hematological parameters and coronary angiography data between elevated RBG group and control group

\begin{tabular}{|c|c|c|c|}
\hline Variables & Elevated RBG group $(n=265)$ & Control group $(n=693)$ & $P$ value \\
\hline Gender(man) & $193(72.8 \%)$ & $551(79.5 \%)$ & $0.026^{*}$ \\
\hline Age & $64.08 \pm 12.94$ & $61.64 \pm 13.47$ & $0.019^{*}$ \\
\hline Height(cm) & $166.71 \pm 7.44$ & $166.78 \pm 7.54$ & 0.92 \\
\hline Weight(kg) & $68.55 \pm 12.18$ & $68.76 \pm 11.38$ & 0.844 \\
\hline $\mathrm{BMI}\left(\mathrm{kg} / \mathrm{m}^{2}\right)$ & $24.93 \pm 3.87$ & $24.44 \pm 3.53$ & 0.132 \\
\hline $\mathrm{SBP}(\mathrm{mmHg})$ & $124.80 \pm 24.80$ & $126.52 \pm 20.83$ & 0.315 \\
\hline $\mathrm{DBP}(\mathrm{mmHg})$ & $76.14 \pm 16.29$ & $76.98 \pm 14.32$ & 0.472 \\
\hline Hypertension & $167(63.0 \%)$ & $384(55.4 \%)$ & $0.033^{*}$ \\
\hline Diabetes & $174(65.7 \%)$ & $88(12.7 \%)$ & $<0.001^{*}$ \\
\hline Previous Ml & $12(4.5 \%)$ & $10(1.4 \%)$ & $0.013^{*}$ \\
\hline Cerebral infarction & $37(14.0 \%)$ & $65(9.4 \%)$ & $0.040^{*}$ \\
\hline CKD & $30(11.3 \%)$ & $49(7.1 \%)$ & $0.032^{*}$ \\
\hline Smoking & $119(44.9 \%)$ & $380(54.8 \%)$ & $0.006^{*}$ \\
\hline \multicolumn{4}{|l|}{ Killip grade } \\
\hline I grade & $158(59.6 \%)$ & $502(72.4 \%)$ & $<0.001^{*}$ \\
\hline II grade & $42(15.8 \%)$ & $112(16.1 \%)$ & 0.906 \\
\hline III grade & $2(0.8 \%)$ & $9(1.3 \%)$ & 0.480 \\
\hline IV grade & $63(23.8 \%)$ & $70(10.1 \%)$ & $<0.001^{*}$ \\
\hline TNI $\mathrm{P}_{50}\left(\mathrm{P}_{25}-\mathrm{P}_{75}\right)(\mathrm{ng} / \mathrm{ml})$ & $17.9(3.2-25)$ & $14(3.53-25)$ & 0.286 \\
\hline Myo $P_{50}\left(P_{25}-P_{75}\right)(n g / m l)$ & $500(241-900)$ & $500(239-900)$ & 0.096 \\
\hline CK-MB P $P_{50}\left(P_{25}-P_{75}\right)(n g / m l)$ & 80 (26.9-292) & $80(44-303.25)$ & 0.406 \\
\hline BNP $P_{50}\left(P_{25}-P_{75}\right)(p g / m l)$ & $216.5(55.9-862)$ & $134(43.3-393.25)$ & $0.002^{*}$ \\
\hline WBC $\left({ }^{*} 10^{\wedge} 9 / L\right)$ & $12.46 \pm 4.61$ & $11.19 \pm 3.68$ & $<0.001^{*}$ \\
\hline $\mathrm{Hb}(\mathrm{g} / \mathrm{L})$ & $133.21 \pm 23.15$ & $135.99 \pm 20.71$ & 0.098 \\
\hline PLT $\left(* 10^{\wedge} 9 / \mathrm{L}\right)$ & $207.48(146.4-289.3)$ & $204.68(130.5-275.2)$ & 0.564 \\
\hline $\mathrm{RBG}(\mathrm{mmol} / \mathrm{L})$ & $16.34(13.2-20.6)$ & $7.35(6.8-9.6)$ & $<0.001^{*}$ \\
\hline $\operatorname{ALT} P_{50}\left(P_{25}-P_{75}\right)(U / L)$ & $53(34-82)$ & $44(30-68.75)$ & $0.001^{*}$ \\
\hline AST $P_{50}\left(P_{25}-P_{75}\right)(I U / L)$ & $174.5(79-323)$ & $157.5(76.75-262.25)$ & 0.073 \\
\hline $\operatorname{Scr} P_{50}\left(P_{25}-P_{75}\right)(\mu \mathrm{mol} / \mathrm{L})$ & $81(71-105.5)$ & $80.5(69-92)$ & 0.1 \\
\hline $\begin{array}{l}\text { eGFR } P_{50}\left(P_{25}-P_{75}\right) \\
\left(\mathrm{ml} / \mathrm{min} / 1.73 \mathrm{~m}^{2}\right)\end{array}$ & 77.18 (54.95-96.24) & 82.37 (68.89-97.27) & $0.022^{*}$ \\
\hline $\mathrm{UA}(\mu \mathrm{mol} / \mathrm{L})$ & 364.18 (318.3-468.6) & 366.75 (314.6-453.3) & 0.079 \\
\hline $\mathrm{FBG}(\mathrm{mmoL} / \mathrm{L})$ & $12.00 \pm 5.47$ & $6.45 \pm 2.02$ & $<0.001^{*}$ \\
\hline $\mathrm{TG}(\mathrm{mmoL} / \mathrm{L})$ & $2.12(1.68-3.39)$ & $1.67(1.32-2.87)$ & $0.004^{*}$ \\
\hline $\mathrm{TC}(\mathrm{mmoL} / \mathrm{L})$ & $4.27(3.03-5.97)$ & $4.48(2.97-5.42)$ & $0.044^{*}$ \\
\hline $\mathrm{HDL}-\mathrm{c}(\mathrm{mmoL} / \mathrm{L})$ & $1.02(0.82-1.88)$ & $1.13(1.01-1.96)$ & $<0.001^{*}$ \\
\hline $\mathrm{LDL}-\mathrm{c}(\mathrm{mmoL} / \mathrm{L})$ & $2.62(2.38-3.42)$ & $2.80(2.07-3.36)$ & $0.017^{*}$ \\
\hline LVEF (\%) & $0.54 \pm 0.12$ & $0.58 \pm 0.11$ & $<0.0010^{*}$ \\
\hline Aspirin & $263(99.2 \%)$ & $681(98.3 \%)$ & 0.26 \\
\hline Clopidogrel & $21(7.9 \%)$ & 95 (13.7\%) & $0.014^{*}$ \\
\hline Ticagrelor & $244(\%)$ & 598 (86.3\%) & $0.014^{*}$ \\
\hline ACEI/ARB & 112 (92.1\%) & $370(53.4 \%)$ & $0.002^{*}$ \\
\hline$\beta$-blocker & $214(80.8 \%)$ & $580(83.7 \%)$ & 0.28 \\
\hline Statin & 265 (100\%) & 688 (99.3\%) & 0.166 \\
\hline
\end{tabular}


Table 1 Comparison of baseline data, hematological parameters and coronary angiography data between elevated RBG group and control group (Continued)

\begin{tabular}{llll}
\hline Variables & Elevated RBG group $(n=265)$ & Control group $(n=693)$ & $P$ value \\
\hline CCB & $16(6.0 \%)$ & $44(6.3 \%)$ & 0.338 \\
Furosemide & $72(27.1 \%)$ & $177(25.8 \%)$ & 0.424 \\
Antisterone & $70(26.4 \%)$ & $179(\%)$ & 0.261 \\
IABP & $28(10.6 \%)$ & $35(5.1 \%)$ & $0.002^{*}$ \\
CABG & $5(1.9 \%)$ & $8(1.2 \%)$ & 0.381 \\
Coronary lesions & & & $<0.001^{*}$ \\
$\quad$ Single vessel lesion & $44(16.6 \%)$ & $192(27.7 \%)$ & $0.012^{*}$ \\
$\quad$ Double vessel lesions & $95(35.8 \%)$ & $310(44.7 \%)$ & 0.434 \\
$\quad 126(47.5 \%)$ & & 0.374 \\
Triple vessel lesions & & $415(59.9 \%)$ & 0.356 \\
$\quad$ Single stent & $167(63.0 \%)$ & $133(19.2 \%)$ & $0.023^{*}$ \\
$\quad$ Two or more stents & $44(5.3 \%)$ & $6.0 \%)$ & \\
$\quad$ Left main lesion & $37(14.0 \%)$ & & \\
\hline
\end{tabular}

$B M I$ Body Mass Index, SBP Systolic blood pressure, DBP Diastolic blood pressure, CKD Chronic kidney diseases, TNI Troponin, Myo Myohemoglobin, CK-MB Creatine Kinase-MB, BNP Brain natriuretic peptide, WBC White blood cell, Hb Hemoglobin, PLT Platelet, RBG Random blood glucose, ALT Alanine transaminase, AST Aspartate transaminase, Scr Serum creatinine, eGFR Estimated glomerular filtration rate, UA Uric Acid, FBG Fasting blood glucose, TG Triglyceride, TC Total cholesterol, $H D L-c$ High density lipoprotein-cholesterol, $L D L-c$ Low density lipoproten-cholesterol, $L V E F$ Left ventricular ejection fraction, CCB Calcium channel blocker, IABP Intra-aortic ballon pump, CABG Coronary Artery Bypass Grafting

The average RBG and FBG in AMI patients who died in hospital were 15.29 and $13.47 \mathrm{mmol} / \mathrm{L}$, respectively. The average RBG and RBG levels in normal RBG and normal FBG group were 9.32 and $7.63 \mathrm{mmol} / \mathrm{L}$, respectively (Fig. 2).

The AUC and 95\%CI of RBG and FBG for predicting cardiac shock were 0.703、0.670-0.734 $(P<0.0001)$; 0.746, 0.717-0.771 $(P<0.0001)$ respectively, the cut-off value were $13.14,6.96 \mathrm{mmol} / \mathrm{L}$ respectively, and the corresponding sensitivity and specificity were $50.0,83.43 \%$; $79.59,62.68 \%$. There was no statistical difference in predicting cardiac shock of RBG and FBG $(P=0.5704)$ (Fig. 3).

The AUC and 95\% CI of RBG and FBG for predicting malignant arrhythmia were $0.740,0.709-0.770 \quad(P<$ $0.0001)$; $0.798,0.771-0.824(\mathrm{P}<0.0001)$ respectively, the cut-off value were $13.28,7.19 \mathrm{mmol} / \mathrm{L}$ respectively, and the corresponding sensitivity and specificity were $66.7 \% 、 82.4 \% ; 93.7 \% 、 63.6 \%$. There was no statistical difference in predicting malignant arrhythmia of RBG and FBG $(P=0.6540)$ (Fig. 4).

\section{Subgroup analysis for nondiabetic patients}

In nondiabetic AMI patients, the AUC and $95 \% \mathrm{CI}$ of RBG and FBG for predicting in-hospital death were $0.808 、 0.774-0.839 \quad(P<0.0001) ; \quad 0.891 、 0.865-0.914$ $(\mathrm{P}<0.0001)$ respectively, the cut-off value were 8.00 , $7.35 \mathrm{mmol} / \mathrm{L}$ respectively, and the corresponding sensitivity and specificity were $82.6,67.0 \% ; 88.89,86.35 \%$. There was no statistical difference in predicting inhospital death of RBG and FBG $(P=0.762)$ (Fig. 5).

\section{Discussion}

Our research showed that the incidences of elevated RBG and elevated fasting blood glucose were significantly high, in which non-diabetics accounted for relatively high proportion. Elevated RBG and elevated FBG group have significantly higher incidence of in-hospital death, malignant arrhythmia, hemorrhage and cardiac shock compared with normal glucose patients. The incidence of nonfatal recurrent MI target vessel revascularization and stroke were all extremely low, hence, no significance was found in elevated glucose and normal glucose group. ROC curve indicated that FBG and RBG had outstanding predictive value in in-hospital death, hemorrhage, cardiogenic shock and malignant arrhythmia during hospitalization. The sensitivity and specificity can be as high as 90.62 , and $68.05 \%$ when predicting the possibility of the in-hospital death AMI patient's FBG over $7.35 \mathrm{mmol} / \mathrm{L}$. The AUC area of the FBG predicting adverse events during hospitalization was significantly higher than that of the RBG, but no statistically significant difference was found between them in terms of predictive value. A multicenter large sample study is needed to further clarify the difference in predictive value on poor prognosis. The ROC curve in subgroup analysis showed that RBG and FBG have higher predictive value for in-hospital death in non-diabetic patients with AMI. When FBG is $7.35 \mathrm{mmol} / \mathrm{L}$, the corresponding sensitivity and specificity are as high as 88.89 and $86.35 \%$. Vergès $B$ and his colleagues underscores the high prevalence of IFG (25\%) and highlighted the clinical relevance of $6.1 \mathrm{mmol} / \mathrm{l}$, as a cutoff value to define 
Table 2 Comparison of baseline data, hematological parameters and coronary angiography data in elevated FBG group and control group

\begin{tabular}{|c|c|c|c|}
\hline Variables & Elevated FBG group $(n=589)$ & Normal FBG group $(n=369)$ & $P$ value \\
\hline Gender(man) & $433(73.5 \%)$ & $303(82.1 \%)$ & $0.002^{*}$ \\
\hline Age & $62.91 \pm 13.01$ & $61.72 \pm 13.84$ & 0.185 \\
\hline Height(cm) & $166.77 \pm 7.64$ & $166.70 \pm 7.20$ & 0.087 \\
\hline Weight(kg) & $69.02 \pm 12.20$ & $68.15 \pm 11.73$ & 0.319 \\
\hline $\mathrm{BMI}\left(\mathrm{kg} / \mathrm{m}^{2}\right)$ & $24.77 \pm 3.70$ & $24.09 \pm 3.71$ & $0.012^{*}$ \\
\hline $\mathrm{SBP}(\mathrm{mmHg})$ & $127.08 \pm 23.18$ & $125.34 \pm 19.14$ & 0.235 \\
\hline $\mathrm{DBP}(\mathrm{mmHg})$ & $76.89 \pm 15.05$ & $76.44 \pm 13.84$ & 0.467 \\
\hline Hypertension & $349(59.3 \%)$ & $202(54.7 \%)$ & 0.169 \\
\hline Diabetes & $242(41.1 \%)$ & $20(5.4 \%)$ & $<0.001^{*}$ \\
\hline Previous Ml & $15(2.5 \%)$ & $7(1.9 \%)$ & 0.514 \\
\hline Cerebral infarction, & $86(14.6 \%)$ & $16(4.3 \%)$ & $<0.001^{*}$ \\
\hline CKD & $54(9.2 \%)$ & $25(6.8 \%)$ & 0.190 \\
\hline Smoking & $283(48.0 \%)$ & $216(58.5 \%)$ & $0.002^{*}$ \\
\hline \multicolumn{4}{|l|}{ Killip grade } \\
\hline I grade & $367(62.3 \%)$ & $293(79.4 \%)$ & $<0.001^{*}$ \\
\hline II grade & $103(17.5 \%)$ & $51(13.8 \%)$ & 0.133 \\
\hline III grade & $9(1.5 \%)$ & $2(0.5 \%)$ & 0.163 \\
\hline IV grade & 99 (16.8\%) & $34(9.2 \%)$ & $<0.001^{*}$ \\
\hline TNI $P_{50}\left(P_{25}-P_{75}\right)(n g / m l)$ & $17(3.98-25)$ & $11(2.3-25)$ & $0.002^{*}$ \\
\hline Myo $P_{50}\left(P_{25}-P_{75}\right)(n g / m l)$ & $500(219.75-900)$ & $500(206.25-900)$ & $0.016^{*}$ \\
\hline CK-MB P $P_{50}\left(P_{25}-P_{75}\right)(n g / m l)$ & 80 (36.45-297) & $80(37.5-246.5)$ & 0.260 \\
\hline BNP $P_{50}\left(P_{25}-P_{75}\right)(p g / m l)$ & $173(49.75-587.5)$ & $112(41.45-347.5)$ & $0.001^{*}$ \\
\hline WBC $\left({ }^{*} 10^{\wedge} 9 / L\right)$ & $12.29 \pm 4.45$ & $10.47 \pm 2.94$ & $<0.001^{*}$ \\
\hline $\mathrm{Hb}(\mathrm{g} / \mathrm{L})$ & $134.5 \pm 23.11$ & $135.99 \pm 20.71$ & 0.066 \\
\hline $\operatorname{PLT}\left({ }^{*} 10^{\wedge} 9 / \mathrm{L}\right)$ & $209.87(160.3-268.3)$ & 201.7 (170.4-259.2) & 0.051 \\
\hline $\mathrm{RBG}(\mathrm{mmol} / \mathrm{L})$ & $11.25(9.3-16.5)$ & $7.22(6.8-10.0)$ & $<0.001^{*}$ \\
\hline ALT $\left.P_{50}\left(P_{25}-P_{75}\right) \mid U / L\right)$ & $48(33-79)$ & $39(29-59)$ & $<0.001^{*}$ \\
\hline AST $P_{50}\left(P_{25}-P_{75}\right)(I U / L)$ & $145(60-219)$ & $171(89-309)$ & $<0.001^{*}$ \\
\hline $\operatorname{Scr} P_{50}\left(P_{25}-P_{75}\right)(\mu \mathrm{mol} / \mathrm{L})$ & 81 (67-98) & $80(72-91)$ & 0.862 \\
\hline $\begin{array}{l}\text { eGFR } P_{50}\left(P_{25}-P_{75}\right) \\
\left(\mathrm{ml} / \mathrm{min} / 1.73 \mathrm{~m}^{2}\right)\end{array}$ & $80.9(62.22-97.88)$ & $81.7(69.2-96.2)$ & 0.704 \\
\hline $\mathrm{UA}(\mu \mathrm{mol} / \mathrm{L})$ & $376.41(280.3-390.3 .2)$ & $365.35(249.5-378.4)$ & 0.152 \\
\hline $\mathrm{FBG}(\mathrm{mmoL} / \mathrm{L})$ & $9.79 \pm 2.67$ & $5.22 \pm 0.52$ & $<0.001^{*}$ \\
\hline $\mathrm{TG}(\mathrm{mmoL} / \mathrm{L})$ & $1.83(1.28-2.56)$ & $1.64(0.89-2.06)$ & 0.051 \\
\hline $\mathrm{TC}(\mathrm{mmoL} / \mathrm{L})$ & $4.46(4.13-5.84)$ & $4.42(4.02-5.73)$ & 0.667 \\
\hline $\mathrm{HDL}-\mathrm{c}(\mathrm{mmoL} / \mathrm{L})$ & $1.12(0.83-1.46)$ & $1.07(0.95-1.47)$ & $0.046^{*}$ \\
\hline LDL-c(mmoL/L) & $2.77(2.19-3.07)$ & $2.80(2.26-3.26)$ & 0.682 \\
\hline LVEF (\%) & $0.53 \pm 0.38$ & $0.68 \pm 0.34$ & $<0.001^{*}$ \\
\hline Aspirin & $581(98.6 \%)$ & 364 (98.6\%) & 0.997 \\
\hline Clopidogrel & 61 (10.4\%) & 55 (14.9\%) & $0.028^{*}$ \\
\hline Ticagrelor & $528(89.6 \%)$ & $314(85.1 \%)$ & $0.028^{*}$ \\
\hline ACEI/ARB & 277 (47.0\%) & 205 (55.6\%) & $0.01^{*}$ \\
\hline$\beta$-blocker & 494 (83.9\%) & 300 (81.3\%) & 0.304 \\
\hline Statin & $586(99.5 \%)$ & 367 (99.5\%) & 0.946 \\
\hline
\end{tabular}


Table 2 Comparison of baseline data, hematological parameters and coronary angiography data in elevated FBG group and control group (Continued)

\begin{tabular}{llll}
\hline Variables & Elevated FBG group $(n=589)$ & Normal FBG group $(n=369)$ & $P$ value \\
\hline CCB & $30(5.1 \%)$ & $30(8.1 \%)$ & 0.059 \\
Furosemide & $174(29.5 \%)$ & $75(20.3 \%)$ & $77(20.9 \%)$ \\
Antisterone & $172(29.2 \%)$ & $12(3.3 \%)$ & $0.002^{*}$ \\
IABP & $51(8.7 \%)$ & $3(0.8 \%)$ & $0.004^{*}$ \\
CABG & $10(17.1 \%)$ & & $0.001^{*}$ \\
Coronary lesions & & $135(36.6 \%)$ & 0.249 \\
$\quad$ Single vessel lesion & $101(29.0 \%)$ & $115(31.2 \%)$ & $152(41.2 \%)$ \\
$\quad 171(\%)$ & & 0.483 \\
$\quad$ Double vessel lesions & $284(48.2 \%)$ & $242(65.6 \%)$ & $0.034^{*}$ \\
Triple vessel lesions & & $53(14.4 \%)$ & $0.011^{*}$ \\
$\quad$ Single stent & $340(57.7 \%)$ & $24(6.5 \%)$ & $0.009^{*}$ \\
$\quad$ Two or more stents & $124(21.1 \%)$ & & $0.002^{*}$ \\
$\quad$ Left main lesion & $75(12.7 \%)$ & & \\
\hline
\end{tabular}

short-term outcome in AMI patients [17]. Random blood glucose and fasting blood glucose are both clinically commonly used and easily available indicators. Our research showed that FBG, along with RBG, has certain clinical value on risk stratification and prognosis evaluation in patients with AMI. In addition, we also provide random blood glucose and fasting blood glucose thresholds that can be used to predict adverse events in hospitals including death, which is of significant use in clinical practice.

Acute hyperglycemia refers to the transient high blood glucose that occurs during the development of disease. There is no consensus on the appropriate definition of hyperglycemia for patients with AMI, blood glucose of $10.0 \mathrm{mmol} / \mathrm{L}$ or $11.0 \mathrm{mmol} / \mathrm{L}$ on admission is used most frequently to define acute hyperglycemia. Elevated RBG belongs to hyperglycemia, the prevalence of elevated RBG in AMI varies a lot from study to study according to its definition [5]. In general, about half of patients with STEMI have elevated RBG [18]. Plenty of studies have demonstrated that patients with AMI and elevated RBG on admission have high incidence of mortality, low left ventricular ejection fraction and short-term poor prognosis in AMI patients [19]. Tamer M. Moustafa discovered that elevated admission blood glucose level was an independent risk factor in prediction of cardiac events and mortality, admission glucose was closely associated with poor adverse outcome and more severe multi-vessel coronary lesions in STEMI patients without diabetes. They proposed that the cut-off value of admission glucose was $160 \mathrm{mg} / \mathrm{dl}$ [8]. Reviewing 141,680 patients aged $\geq 65$ years with AMI, the Cooperative Cardiovascular Project revealed that the 30-day and 1year mortality rates were linearly associated with admission blood glucose level [20]. JACSS Investigators enrolled 3750 AMI patients, demonstrating a linear relation between admission blood glucose level and inhospital mortality in nondiabetic patients [21]. In a meta-analysis of 1856 AMI patients (5), the relative risk of in-hospital death in non-diabetic patients with elevated RBG was 3.9 times higher than patients with normal blood glucose $(95 \% \mathrm{CI}=2.9-5.4)$, diabetic patients combined with admission elevated RBG had 1.7 times higher risk of death during hospitalization than that in normal population (95\% CI $=1.2-2.4)$ [5]. Although it is well known that elevated admission blood glucose level

Table 3 Comparison of incidence of in-hospital adverse events in patients with elevated RBG, elevated FBG and control group

\begin{tabular}{lllllll}
\hline Variables & Elevated RBG group & Normal RBG group & $P$ value & Elevated FBG group & Normal FBG group & $P$ value \\
\hline Death & $56(265)$ & $24(693)$ & $<0.001^{*}$ & $72(589)$ & $5(369)$ & $<0.001^{*}$ \\
Nonfatal recurrent myocardial infarction & $6(265)$ & $4(693)$ & 0.052 & $7(589)$ & $3(369)$ & 0.818 \\
Stroke & $1(265)$ & $0(693)$ & 0.617 & $1(589)$ & $0(369)$ & 1 \\
Hemorrhage & $9(265)$ & $14(693)$ & $0.014^{*}$ & $20(589)$ & $3(369)$ & $0.013^{*}$ \\
Cardiac shock & $57(265)$ & $49(693)$ & $<0.001^{*}$ & $89(589)$ & $17(369)$ & $<(369)$ \\
Malignant arrhythmia & $25(265)$ & $13(693)$ & $<0.001^{*}$ & $32(589)$ & $0.001^{*}$ \\
\hline
\end{tabular}

* $P<0.05$; 
Table 4 Binary logistic regression analysis for in-hospital adverse events

\begin{tabular}{llll}
\hline Variables & OR & $95 \% \mathrm{Cl}$ & $P$ value \\
\hline Gender & 1.17 & $0.93-1.95$ & 0.075 \\
Age & 1.63 & $1.39-2.07$ & $0.037^{*}$ \\
Hypertension & 1.34 & $1.15-1.67$ & $0.039^{*}$ \\
Diabetes & 2.47 & $1.79-3.85$ & $0.043^{*}$ \\
Smoking & 2.453 & $0.75-3.49$ & 0.785 \\
FBG & 1.740 & $1.12-1.98$ & $0.043^{*}$ \\
RBG & 1.205 & $1.04-1.63$ & $0.048^{*}$
\end{tabular}

RBG Random blood glucose, FBG Fasting blood glucose

is closely associated with poor prognosis in AMI patients, studies have shown that persistent hyperglycemia during acute myocardial infarction has a better predictive value for in-hospital mortality than admission glucose. Considering the simplicity of clinical implementation and calculation, the average blood glucose level seems to be the best method for assessing the prognosis of AMI patients with hyperglycemia. The J-shaped curve of mean blood glucose level and in-hospital mortality showed that not only hyperglycemia, hypoglycemia can also increase mortality in AMI patients [7]. Studies need to further clarify the relationship between hyperglycemia in AMI and poor prognosis.

Elevated fasting glucose was also associated with the risk of cardiovascular disease [22]. With the increasement of blood glucose level, even below the current diagnosis criteria for diabetes, the risk of developing cardiovascular disease increases [23]. The National Hospital

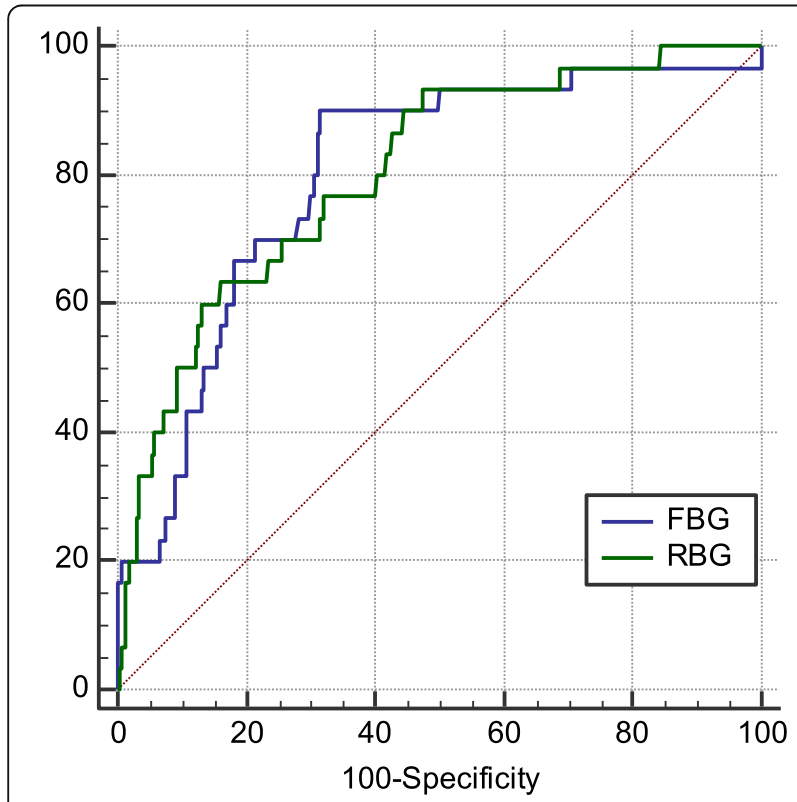

Fig. 1 The ROC cure of RBG and FBG for predicting in-hospital death of Singapore conducted a five-year follow-up of 2295 patients with newly diagnosed IFG, finding that 492 (21.4\%) subjects developed T2DM within 5 years, and 20 (0.9\%) developed AMI [24]. A retrospective multicenter 5-year cohort study performed on 9161 Chinese IFG subjects attending 23 general outpatient clinics showed 1998 participants eventually developed T2DM. The 5year cumulative incidence was 0.218 [25]. A prospective study enrolling 2733 consecutive AMI subjects underwent percutaneous coronary intervention (PCI)indicated impaired glucose tolerance bearing similar long-term prognosis as diabetes [26]. These researches showed the association between elevated fasting blood glucose and diabetes, elevated fasting blood glucose significantly increases the incidence of suffering AMI. Therefore, we must pay attention to elevated glucose, even not yet reached the diagnostic criteria for diabetes.

Mechanically speaking, hyperglycemia has a direct detrimental effect on ischemic myocardium through several mechanisms, including oxidative stress, inflammation, apoptosis, endothelial dysfunction, hypercoagulation, platelet aggregation and impairment of ischemic preconditioning. Specifically, acute hyperglycemia exaggerates inflammation by the oxidative mechanism [27]. Animal experiments show that SGLT2 inhibitors can reduce the mortality of myocardial infarction in diabetic mice through cardiac energy metabolism and protective modification of antioxidant proteins, suggesting that hyperglycemia is associated with energy metabolism disorder and oxidative stress in myocardial infarction [28]. Risso reported that intermittent high glucose enhanced apoptosis of human endothelial cells [29]. Besides, acute hyperglycemia can lead to endothelial dysfunction, hyperglycemia also affects coronary collateral blood flow [30]. Hyperglycemia also stimulates blood clotting and platelet aggregation, which can upregulate coagulation activation markers including thrombin antithrombin complex and soluble tissue factor [31].

In addition to RBG and FBG, there are some other studies focusing on the relationship between blood glucose and AMI. Considering that the risk of adverse events such as death and recurrent angina in AMI patients with diabetes is quite different, Suzanne V. Arnold, et al. developed a prediction model for long-term mortality and angina to stratify AMI patients with diabetes [9]. Considering the change in FBG concentrations over time, Cheng Jin conducted a prospective cohort study included 68,297 non-diabetic participants, they found that discrete FBG trajectories were significantly related to subsequent risk of MI. These observations suggest that trajectories of FBG may be significant for predicting MI and other cardiovascular risk [32]. Su G also demonstrated that elevated admission glycemic variability appears more important than admission glucose 


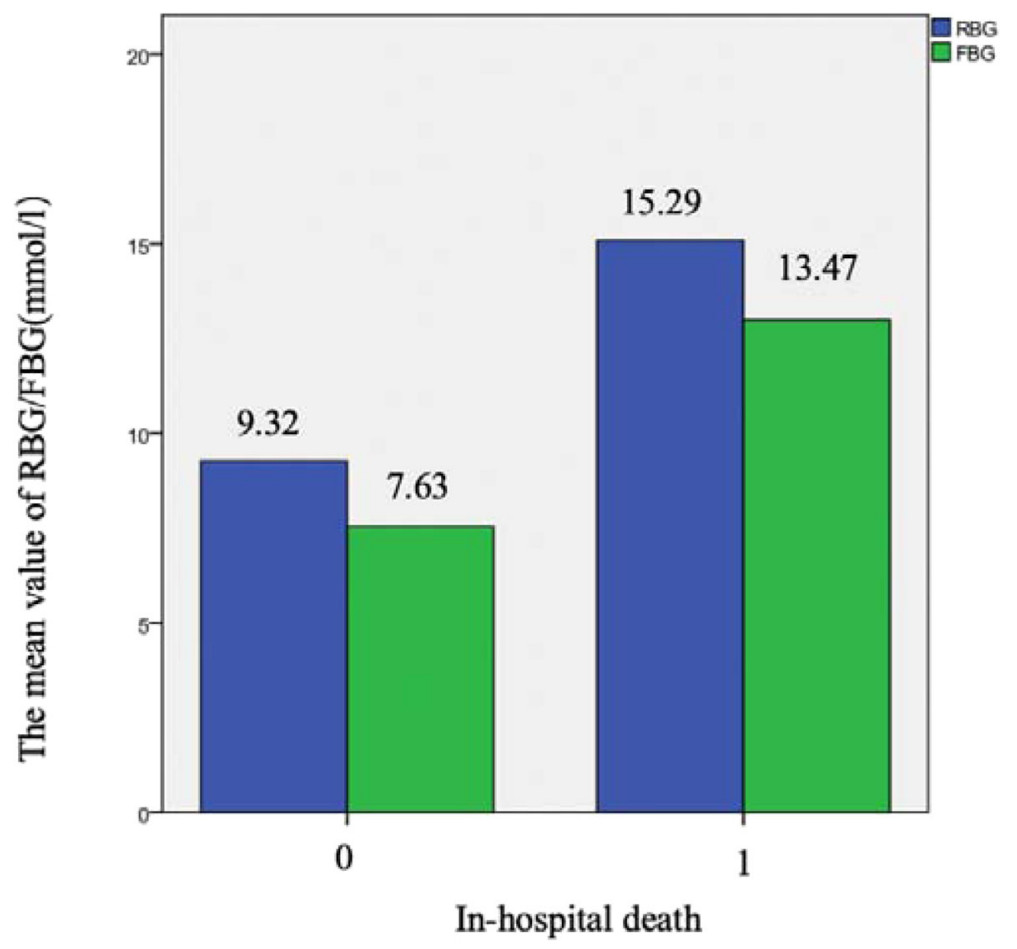

Fig. 2 The mean of RBG and FBG in in-hospital death and control group

in predicting 1-year MACE in AMI patients [33]. In addition, postprandial hyperglycemia also acts as an accelerating factor in atherosclerosis and other cardiovascular disease [34].

When it comes to the treatment for hyperglycemia, recent randomized controlled trial of DPP-4 inhibitors in

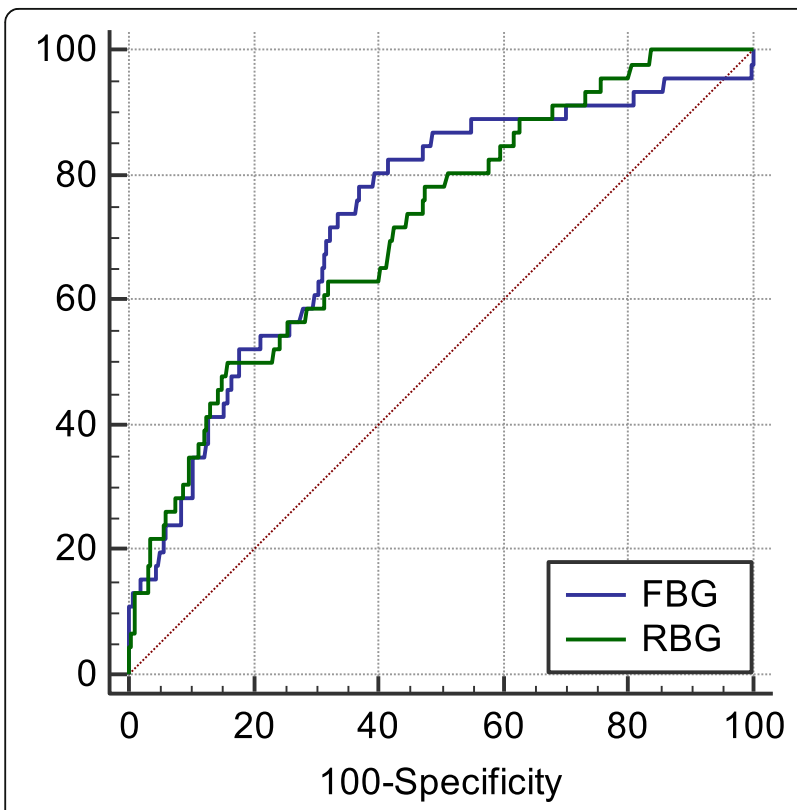

Fig. 3 The ROC cure of RBG and FBG for predicting cardiac shock
T2DM patients after acute coronary syndrome didn't show beneficial effects on cardiovascular outcomes [35]. Continuous insulin infusion is recommended as first-line treatment for AMI patients combined with acute hyperglycemia, taking account of the safety and efficacy,

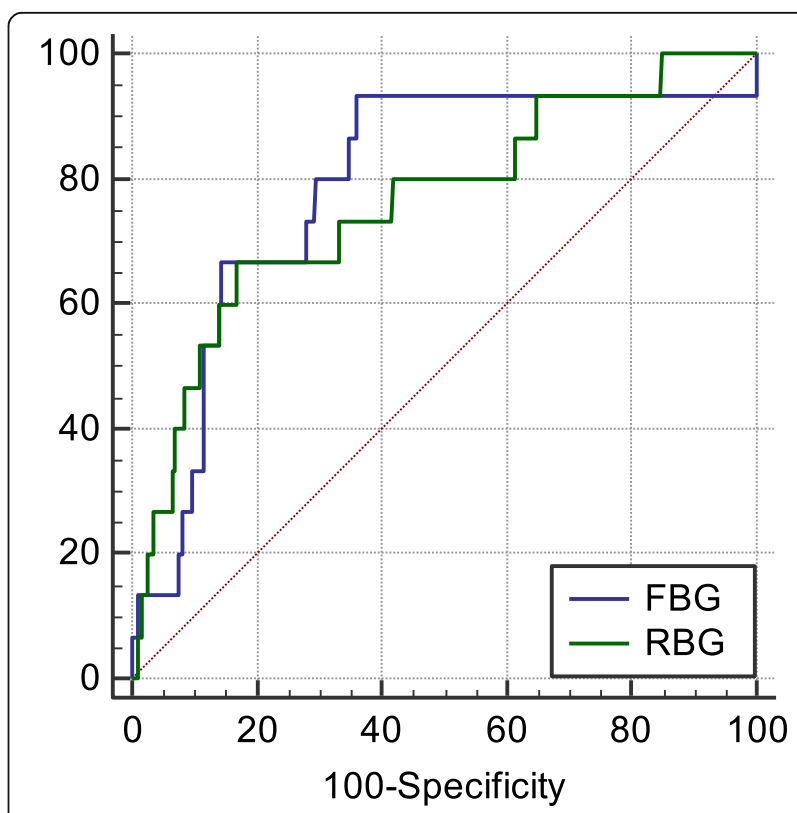

Fig. 4 The ROC curve of RBG and FBG for predicting malignant arrhythmia 


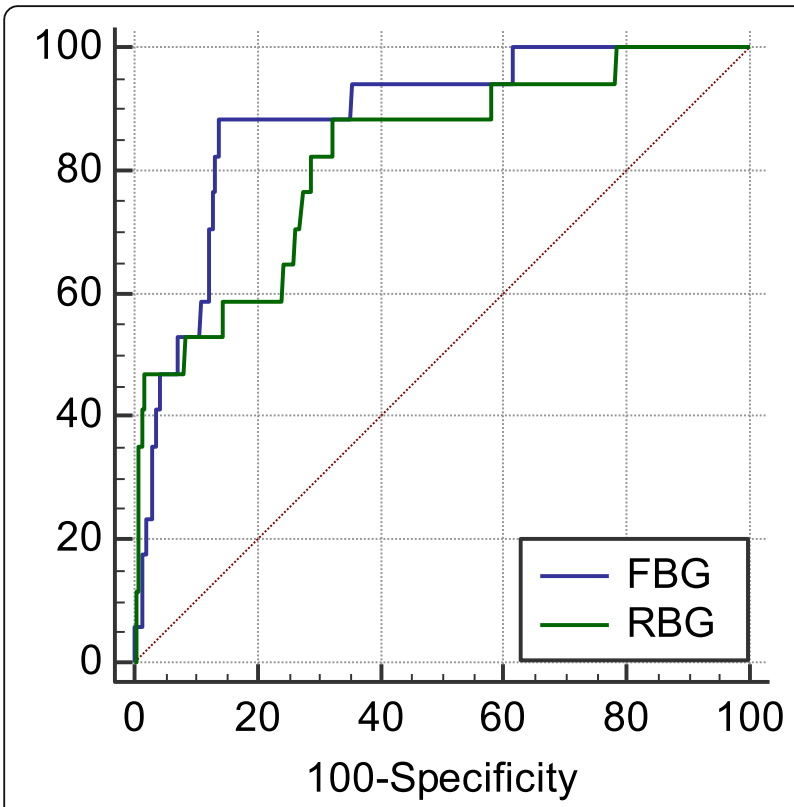

Fig. 5 The ROC curve of RBG and FBG for predicting death in nondiabetic patients

guidelines recommend taking insulin-based regimen to achieve and maintain glucose levels $<10.0 \mathrm{mmol} / \mathrm{l}$, and emphasize avoiding hypoglycemia [36].

\section{Conclusion}

Our study demonstrates that elevated RBG and elevated FBG are very common in AMI patients, among them many patients non-diabetic. Both RBG and FBG are closely related to poor in-hospital prognosis. RBG and FBG have significant predictive value in adverse events during hospitalization, besides, RBG and FBG share similar predictive value on in-hospital adverse events. Finally, we provide the threshold for RBG and FBG to predict the adverse events in hospital, which has certain value in clinical work. This research still has the following shortcomings: Firstly, this study is a single-center retrospective and observational design, large-scale multicenter prospective RCT design needs to be carried out to further evaluate the predictive value of RBG, FBG on in-hospital poor prognosis; Secondly, Long-term followup is requisite to evaluate long-term adverse effects of RBG and FBG and blood glucose fluctuations.

\section{Abbreviations \\ AMI: Acute myocardial infarction; AUC: Area under curve; CABG: Coronary artery bypass grafting; FBG: Fasting blood glucose; IABP: Intra-aortic balloon pump; MACCE: Major adverse cardiovascular and cerebrovascular events; PCI: Percutaneous coronary intervention; RBG: Random blood glucose; STEMI: ST-segment elevation acute myocardial infarction; T2DM: Type 2 diabetes mellitus}

\section{Acknowledgements}

We thank all authors for reviewing, statistical analyses and all the participants for their contributions.

\section{Authors' contributions}

QYH conceived, designed the study and drafted the manuscript. QY, YGL and WD recruited the participants and collected the data. LEF and HJT analysed and interpreted the data. TCC critically revised the manuscript. All authors read and approved the final manuscript.

\section{Funding}

This work was supported by National Natural Science Foundation of China under Grant No. 81600227. The funders had no role in study design, data collection and analysis, preparation of the manuscript or the decision to submit the article for publication.

\section{Availability of data and materials}

The data that support the findings of this study are available from Zhongda Hospital, the data are available from the authors upon reasonable request and with permission from Zhongda Hospital.

\section{Ethics approval and consent to participate}

All participants provided written consent before entering the study, and approval was obtained from the Human Subjects Committee at the Zhongda Hospital, Southeast University.

\section{Consent for publication}

Not applicable.

\section{Competing interests}

The authors declare that they have no competing interests.

\section{Author details}

'Medical school of Southeast University, Nanjing 210009, People's Republic of China. ${ }^{2}$ Department of Cardiology, Zhongda Hospital affiliated to Southeast University, Nanjing 210009, People's Republic of China.

Received: 18 November 2019 Accepted: 17 February 2020 Published online: 27 February 2020

\section{References}

1. Miyamoto Y. Could glucose management after acute myocardial infarction cure myocardial damage? Circ J. 2014;78:67-8.

2. Fox CS, Coady S, Sorlie PD, D'Agostino RB Sr, Pencina MJ, Vasan RS, Meigs JB, Levy D, Savage PJ. Increasing cardiovascular disease burden due to diabetes mellitus: the Framingham heart study. Circulation. 2007;115:154450 .

3. Kannel WB, McGee DL. Diabetes and cardiovascular-disease - Framinghamstudy. JAMA-J Am Med Assoc. 1979;241:2035-8.

4. Morrish NJ, Wang SL, Stevens LK, Fuller JH, Keen H. Mortality and causes of death in the WHO multinational study of vascular disease in diabetes. Diabetologia. 2001:44(Suppl 2):S14-21.

5. Capes SE, Hunt D, Malmberg K, Gerstein HC. Stress hyperglycaemia and increased risk of death after myocardial infarction in patients with and without diabetes: a systematic overview. Lancet. 2000;355:773-8.

6. Modan B, Schor S, Shani M. Acute myocardial infarction. Prognostic value of white blood cell count and blood glucose level. Jama. 1975;233:266-7.

7. Kosiborod M, Inzucchi SE, Krumholz HM, Xiao L, Jones PG, Fiske S, Masoudi FA, Marso SP, Spertus JA. Glucometrics in patients hospitalized with acute myocardial infarction: defining the optimal outcomes-based measure of risk. Circulation. 2008;117:1018-27.

8. Moustafa TM. Utility of admission blood glucose level in prediction of shortterm course and extent of coronary artery occlusion in non-diabetic patients with ST segment elevation myocardial infarction. IJC Metab Endocr. 2017;14:16-20.

9. Arnold SV, Spertus JA, Jones PG, McGuire DK, Lipska KJ, Xu Y, Stolker JM, Goyal A, Kosiborod M. Predicting adverse outcomes after myocardial infarction among patients with diabetes mellitus. Circ Cardiovasc Qual Outcomes. 2016;9:372-9.

10. Suleiman M, Hammerman H, Boulos M, Kapeliovich MR, Suleiman A, Agmon Y, Markiewicz W, Aronson D. Fasting glucose is an important independent risk factor for 30-day mortality in patients with acute myocardial infarction: a prospective study. Circulation. 2005;111:754-60.

11. Barr EL, Zimmet PZ, Welborn TA, Jolley D, Magliano DJ, Dunstan DW, Cameron AJ, Dwyer T, Taylor HR, Tonkin AM, et al. Risk of cardiovascular 
and all-cause mortality in individuals with diabetes mellitus, impaired fasting glucose, and impaired glucose tolerance: the Australian diabetes, obesity, and lifestyle study (AusDiab). Circulation. 2007;116:151-7.

12. Park C, Guallar E, Linton JA, Lee DC, Jang Y, Son DK, Han EJ, Baek SJ, Yun $Y D$, Jee $S H$, et al. Fasting glucose level and the risk of incident atherosclerotic cardiovascular diseases. Diabetes Care. 2013;36:1988-93.

13. Levitzky YS, Pencina MJ, D'Agostino RB, Meigs JB, Murabito JM, Vasan RS, Fox CS. Impact of impaired fasting glucose on cardiovascular disease: the Framingham heart study. J Am Coll Cardiol. 2008;51:264-70.

14. Wang $Y Q$, Wang $C F$, Zhu L, Yuan H, Wu LX, Chen ZH. Ideal cardiovascular health and the subclinical impairments of cardiovascular diseases: a crosssectional study in central South China. BMC Cardiovasc Disord. 2017;17:269.

15. Qin Y, Yan G, Qiao Y, Ma C, Liu J, Tang C. Relationship between random blood glucose, fasting blood glucose, and Gensini score in patients with acute myocardial infarction. Biomed Res Int. 2019;2019:9707513.

16. Thygesen K, Alpert JS, Jaffe AS, Chaitman BR, Bax JJ, Morrow DA, White HD. Fourth universal definition of myocardial infarction (2018). Glob Heart. 2018; 13:305-38.

17. Verges B, Zeller M, Dentan G, Beer JC, Laurent $Y$, Janin-Manificat L, Makki H, Wolf JE, Cottin Y. Impact of fasting glycemia on short-term prognosis after acute myocardial infarction. J Clin Endocrinol Metab. 2007:92:2136-40.

18. Kosiborod M, McGuire DK. Glucose-lowering targets for patients with cardiovascular disease focus on inpatient Management of Patients with Acute Coronary Syndromes. Circulation. 2010;122:2736-44.

19. Ishihara M, Inoue I, Kawagoe T, Shimatani Y, Kurisu S, Nishioka K, Umemura T, Nakamura S, Yoshida M. Impact of acute hyperglycemia on left ventricular function after reperfusion therapy in patients with a first anterior wall acute myocardial infarction. Am Heart J. 2003;146:674-8.

20. Kosiborod M, Rathore SS, Inzucchi SE, Masoudi FA, Wang Y, Havranek EP, Krumholz HM. Admission glucose and mortality in elderly patients hospitalized with acute myocardial infarction: implications for patients with and without recognized diabetes. Circulation. 2005;111:3078-86.

21. Ishihara M, Kojima S, Sakamoto T, Kimura K, Kosuge M, Asada Y, Tei C, Miyazaki S, Sonoda M, Tsuchihashi K, et al. Comparison of blood glucose values on admission for acute myocardial infarction in patients with versus without diabetes mellitus. Am J Cardiol. 2009;104:769-74.

22. Levitan EB, Song Y, Ford ES, Liu S. Is nondiabetic hyperglycemia a risk factor for cardiovascular disease? A meta-analysis of prospective studies. Arch Intern Med. 2004;164:2147-55.

23. Danaei G, Lawes CM, Vander Hoorn S, Murray CJ, Ezzati M. Global and regional mortality from ischaemic heart disease and stroke attributable to higher-than-optimum blood glucose concentration: comparative risk assessment. Lancet (London, England). 2006;368:1651-9.

24. Chia DBZ, Wong LY, Liu DYK, Toh M. Predictive factors of developing type 2 diabetes mellitus, acute myocardial infarction and stroke in a cohort with impaired fasting glucose in Singapore. Diabetes Res Clin Pract. 2017;132:5967.

25. Fu SN, Luk W, Wong CK, Cheung KL. Progression from impaired fasting glucose to type 2 diabetes mellitus among Chinese subjects with and without hypertension in a primary care setting. J Diabetes. 2014;6:438-46.

26. Mazurek M, Kowalczyk J, Lenarczyk R, Zielinska T, Sedkowska A, Pruszkowska-Skrzep P, Swiatkowski A, Sredniawa B, Kowalski O, Polonski L, et al. The prognostic value of different glucose abnormalities in patients with acute myocardial infarction treated invasively. Cardiovasc Diabetol. 2012;11:78.

27. Esposito K, Nappo F, Marfella R, Giugliano G, Giugliano F, Ciotola M, Quagliaro L, Ceriello A, Giugliano D. Inflammatory cytokine concentrations are acutely increased by hyperglycemia in humans: role of oxidative stress. Circulation. 2002:106:2067-72.

28. Oshima H, Miki T, Kuno A, Mizuno M, Sato T, Tanno M, Yano T, Nakata K, Kimura $Y$, Abe $K$, et al. Empagliflozin, an SGLT2 inhibitor, reduced the mortality rate after acute myocardial infarction with modification of cardiac Metabolomes and antioxidants in diabetic rats. J Pharmacol Exp Ther. 2019; 368:524-34.

29. Risso A, Mercuri F, Quagliaro L, Damante G, Ceriello A. Intermittent high glucose enhances apoptosis in human umbilical vein endothelial cells in culture. Am J Phys Endocrinol Metab. 2001;281:E924-30.

30. Azuma K, Kawamori R, Toyofuku Y, Kitahara Y, Sato F, Shimizu T, Miura K, Mine T, Tanaka Y, Mitsumata M, et al. Repetitive fluctuations in blood glucose enhance monocyte adhesion to the endothelium of rat thoracic aorta. Arterioscler Thromb Vasc Biol. 2006;26:2275-80.
31. Stegenga ME, van der Crabben SN, Levi M, de Vos AF, Tanck MW, Sauerwein HP, van der Poll T. Hyperglycemia stimulates coagulation, whereas hyperinsulinemia impairs fibrinolysis in healthy humans. Diabetes. 2006:55:1807-12.

32. Jin C, Chen S, Vaidya A, Wu Y, Wu Z, Hu FB, Kris-Etherton P, Wu S, Gao X. Longitudinal change in fasting blood glucose and myocardial infarction risk in a population without diabetes. Diabetes Care. 2017;40:1565-72.

33. Su G, Mi SH, Tao H, Li Z, Yang HX, Zheng H, Zhou Y, Tian L. Impact of admission glycemic variability, glucose, and glycosylated hemoglobin on major adverse cardiac events after acute myocardial infarction. Diabetes Care. 2013:36:1026-32.

34. Kataoka Y, Yasuda S, Morii I, Otsuka Y, Kawamura A, Miyazaki S. Quantitative coronary angiographic studies of patients with angina pectoris and impaired glucose tolerance. Diabetes Care. 2005;28:2217-22.

35. White WB, Cannon CP, Heller SR, Nissen SE, Bergenstal RM, Bakris GL, Perez AT, Fleck PR, Mehta CR, Kupfer $S$, et al. Alogliptin after acute coronary syndrome in patients with type 2 diabetes. N Engl J Med. 2013;369:1327-35.

36. Ishihara M. Acute hyperglycemia in patients with acute myocardial infarction. Circ J. 2012;76:563-71.

\section{Publisher's Note}

Springer Nature remains neutral with regard to jurisdictional claims in published maps and institutional affiliations.
Ready to submit your research? Choose BMC and benefit from:

- fast, convenient online submission

- thorough peer review by experienced researchers in your field

- rapid publication on acceptance

- support for research data, including large and complex data types

- gold Open Access which fosters wider collaboration and increased citations

- maximum visibility for your research: over $100 \mathrm{M}$ website views per year

At BMC, research is always in progress.

Learn more biomedcentral.com/submissions 